\title{
BEST ONLINE INSTRUCTIONAL PRACTICES: REPORT OF PHASE I OF AN ONGOING STUDY
}

\author{
Morris T. Keeton \\ Senior Scholar \\ University of Maryland University College
}

\begin{abstract}
This study examines how best practices in online instruction are the same as, or different from, best practices in face-to-face (F2F) instruction. The book Effectiveness and Efficiency in Higher Education for Adults [1] summarizes some 20 years of research on best practices in F2F instruction. The bases of comparison are principles from the KS\&G material and from Chickering and Gamson's "seven principles for good practice in undergraduate education" [2]. A reason for making these comparisons is that the rapid growth of online instruction promises that online instruction may become the largest source of ongoing higher education. Not surprisingly, interest in assessing the quality of online offerings has also grown $[3,4,5,6]$. The question is increasingly raised: Are postsecondary institutions effectively "doing their old job in a new way?" [7]. One way to answer that question is to analyze the online instructional practices of faculty with the aid of research on patterns of instruction, face-to-face and online. This paper is abbreviated from a February 14, 2002 report by Marisa Collett, Morris Keeton and Vivian Shayne of the Institute for Research and Assessment in Higher Education for the Office of Distance Education and Lifelong Learning at the University of Maryland University College.
\end{abstract}

\section{PRINCIPLES OF BEST PRACTICE}

The book Effectiveness and Efficiency in Higher Education for Adults [1] (herein referred to as KS\&G) undertakes just such an analysis. The book surveys research of the last 20 years, including meta-analyses of studies on different principles of instruction, in search of principles and practices with largest effect sizes in explaining learning gains. Eight principles emerge as a manageable set of principles meeting this criterion. For each of the principles, case studies are cited that apply each principle as effective practices or strategies.

These eight principles, though worded differently, partially overlap and supplement the "seven principles for good practice in undergraduate education" [2] (herein "C\&G"). 
Table 1. Principles from C\&G and from KS\&G

\begin{tabular}{|l|l|}
\hline Chickering and Gamson (C\&G) & Keeton, Sheckley, \& Krejci-Griggs (KS\&G) \\
\hline $\begin{array}{l}\text { 1. Good practice encourages student-faculty } \\
\text { contact. }\end{array}$ & $\begin{array}{l}\text { Make learning goals and one or more paths } \\
\text { to them clear. }\end{array}$ \\
\hline $\begin{array}{l}\text { 2. Good practice encourages cooperation } \\
\text { among students. }\end{array}$ & Use extensive and deliberate practice. \\
\hline 3. Good practice encourages active learning. & Provide prompt and constructive feedback. \\
\hline 4. Good practice gives prompt feedback. & $\begin{array}{l}\text { Provide an optimal balance of challenge and } \\
\text { support that is tailored to the individual } \\
\text { student's readiness and potential. }\end{array}$ \\
\hline 5. Good practice emphasizes time on task. & $\begin{array}{l}\text { Elicit active and critical reflection by } \\
\text { learners on their growing experience base. }\end{array}$ \\
\hline expectations. & $\begin{array}{l}\text { Link inquiries to genuine problems or issues } \\
\text { of high interest to the learners (thus } \\
\text { enhancing motivation and accelerating their } \\
\text { learning). }\end{array}$ \\
\hline $\begin{array}{l}\text { 7. Good practice respects diverse talents and } \\
\text { ways of learning. }\end{array}$ & $\begin{array}{l}\text { Develop learners' effectiveness as learners } \\
\text { early in their education. }\end{array}$ \\
\hline & $\begin{array}{l}\text { Create an institutional environment that } \\
\text { supports and encourages inquiry. }\end{array}$ \\
\hline
\end{tabular}

In terms of feedback, the KS\&G principles add that the feedback needs to be constructive. The KS\&G principle on balancing challenge and support combines the $C \& G$ principles 6 and 7 , encouraging individualization of learning arrangements. A focus on active learning is shared by the two analyses, with KS\&G making explicit the need for critical thinking and including cooperation among students and interaction between teacher and students as ways to foster the active, critical reflection. Finally, KS\&G adds a focus on the institutional climate or environmental press for inquiry as a key to best practice.

The relationship between a principle and appropriate applications is not a simple one. Consider, for example, the principle that an instructor should make clear the learning goals and objectives of a learning experience (course, workshop, training event) and make one or more paths to their achievement clear to students and keep them clear. Among the ways to do so is to state these goals and paths in a syllabus. Students, however, may not know enough about the subject of study to understand the instructor's explanation in the syllabus without further help. Also workshops rarely provide syllabi. So other strategies are required to fulfill this principle. Normally a mix of strategies will work best to this end.

Though a combination of strategies normally yields best learning, the most effective practices will differ from course to course, workshop to workshop, or training goal to training goal. For example, on the principle of clarifying goals and paths to learning, it can be helpful to give students a pre-test that is equivalent psychometrically to the final assessment to be used. Developing such instrumentation, however, is costly in time and demanding of expertise. It may be more practical to devote extra class time to spelling out the instructor's expectations, or to combine the work of clarification with efforts to motivate students by striking deals in which some course time is given to other goals that different students have, in addition to the instructor's goals. For a given instructional principle, there are numerous strategies available for applying the principle. It is not necessary, of course, to use them all in any one instructional effort. On a Likert scale of 1-5, with 5 as most effective, the instructor might rate his or her 
effectiveness at 4.5 while some implementing strategies would be used slightly, if at all (e.g., at 1 or 2 level), and the average use of the list of available strategies might be only 3 .

\section{KEY FINDINGS}

Key findings of the study to date include the following:

- The individual instructor's effectiveness in applying the eight principles of KS\&G is a major factor in adult students' learning and persistence.

- Students need support additional to that of the syllabus in understanding and pursuing the learning objectives of a course or other educational effort.

- Students in online courses expect faculty to be more readily and promptly available at non-class times than F2F students expect of faculty in responding to the students' communications.

- The most effective faculty actively use five or more of the full array of instructional principles so can they elicit the largest learning effects.

- Faculty agreed that teaching well online is more time-consuming than teaching F2F.

\section{A PILOT STUDY OF INSTRUCTIONAL PRACTICES ONLINE}

In the Summer of 2001 a pilot study of instructional practices online was made by the Institute for Research and Assessment in Higher Education (IRAHE) of UMUC. Three procedures made up the study: 1) a profiling of one of their own online courses by eight instructors by use of a draft form of the Instructional Practices Inventory (IPI); 2) a survey of participating instructors' experience as teachers; and 3 ) an interview of those instructors and use of focus groups among them. The courses studied had been recorded in archives that in most instances covered $75 \%$ to $80 \%$ of the activities of each course. Their respective department Deans nominated the faculty participants. The faculty participants had also either received teaching excellence awards, or scored 4.75 or higher on student evaluations of instruction in the courses that had been archived; in other words, they had been recognized as highly effective instructors. These instructors indicated that they used five of the eight principles investigated at an average level above 4 on a 5 -point scale.

Online faculty members are often asked to describe their pedagogical practices and problems associated with such practices $[8,9]$. But such studies typically do not focus on effective online faculty practitioners. Instead, such studies often survey instructors who come from a variety of institutions, are novices at teaching online, and include a variety of instructors who may not have comparable experiences teaching online. Results derived from studies on faculty members who are inexperienced and/or ineffective for some other reason may not be generalizable and may not provide meaningful insight into effective online pedagogy.

The ultimate goal of the Best Online Instructional Practices Study at UMUC is to determine what constitutes effective online practice and ultimately to help faculty improve the quality of their teaching online. Essentially, the IPI (Instructional Practices Inventory) was used to determine how much and how well these strategies for effective course instruction were used in these online classes.

Questionnaire items were designed to operationalize effective instructional learning principles derived from research in a wide range of fields including cognitive psychology, neurophysiology, anthropology, 
and teacher education [1]. Research in the more traditional face-to-face context suggests that adherence to these principles optimizes learning $[10,11,12,13]$. As said, previous research has demonstrated that the use of these particular principles yields the largest learning effects of practices tested [14].

The initial phase of the Best Instructional Practices Study was designed to pilot test the Instructional Practices Inventory (IPI). The IPI follows each of the eight instructional principles with several statements of strategies designed to implement each principle. For each statement participants indicated their level of agreement as to her/his use of it on a scale of one to five (one being "strongly disagree" and 5 being "strongly agree").

In the pilot study each participating instructor served to profile the extent of his/her own and others' use of best instructional practices in a pre-determined archived course. In total, there were four faculty participants from undergraduate programs and four from the graduate school. Disciplines represented in the sample were administration, accounting, computer studies, history, psychology, and technology management.

In this study, faculty participants were also asked to take part in a focus group meeting with other IPI participants. After the initial self-assessment portion of the study, faculty participants completed a peer review of the online archived courses selected for the self-assessment. Online courses profiled in this study were chosen on the basis of (1) the instructor's overall performance ratings on course evaluations, (2) how recent the course was, and (3) archive availability (see Appendix B for a list of the courses profiled).

Results obtained from the teaching background survey, the IPI self-assessment, and comments elicited from phone interviews and focus groups are addressed below, followed by a brief description of faculty participants.

The second phase of this research project focused on results of a peer review by faculty participants of each of the courses included in the study. The IPI was revised on the basis of suggestions made by faculty participants in the first phase of the study and used in the second (peer review) phase of the study.

\section{METHOD}

To understand better the teaching background, philosophies, and perspectives, a teaching background survey was created; an interview protocol for telephone interviews was also created as a follow up to the background survey and responses on the IPI, and discussions from meetings were recorded. The temporal order of administration for all these items and events was as follows: (1) there was an initial meeting of the faculty participants and researchers; (2) at the end of the meeting, faculty participants were given the teaching background survey and given two weeks to complete it; (3) after the background surveys from participants were received, the IPI was administered and participants were asked to complete it within a two week time period; (4) during this time period the telephone interviews were conducted individually; and (5) once participants completed the telephone surveys and staff received the self-assessments on the IPI, a second meeting was held to get feedback from the co-researchers on the IPI.

The meetings with faculty participants were each approximately an hour and half in length. All faculty participants were present at these meetings in some form, either physically or by speakerphone. The first meeting was an introductory meeting describing what the Best Online Practices Study was and what 
participants' responsibilities would be in this study. The second meeting came at the completion of the self-assessments by faculty participants. Within this meeting, participants gave staff their feedback on the IPI and were then given an overview of the second phase of the project, the peer review.

The teaching background survey addressed several aspects of participants' educational background, teaching experience (online and face to face), how they prepare for a course, instructional activities, and instructional emphases. Both the teaching background survey and IPI were filled out individually. The phone interviews, approximately 45 minutes each, were conducted individually with every faculty participant.

Results from the teaching background survey, phone interviews, and focus groups were analyzed and compared with the self-assessment ratings on the IPI.

\section{WHO WERE THE FACULTY?}

Overall, six of the eight faculty participants are adjunct faculty and the remaining two are full-time faculty. Of the adjunct faculty, four are employed in fulltime positions outside the university and the other two did not indicate any other outside employment. Faculty participants have taught for an average of 19 semesters (range $=10-40$ ). They have taught an average of 36 classes during their tenure as instructors (range $=9-112$ ). They have conducted an average of 16 classes online (range $=4-48$ ). In terms of the class profiled using the Instructional Practices Inventory (Version 1), participants have taught this particular class an average of 6 times (range $=1-14$ ).

For three-quarters of the sample, their subject matter expertise is directly related to the subject of the profiled class ( 6 out of 8 of the faculty researchers). Most chose to be instructors for the challenge, to improve their skills and the enjoyment of teaching. Their choices for teaching online vary. One participant noted that he had no other choice but to teach online because UMUC was encouraging online teaching. Others were either interested in the challenge of trying new mediums or for personal development. Still others saw that this was where demand was and they could fit this type of instruction into their work schedule. Most of the faculty participants (5 out of 8 ) have more experience teaching in a face to face context (at least 2 times more experience). Within this more experienced F2F teaching group, two participant members indicated that they also had experience teaching in different distance education formats, such as voicemail and interactive television. Of the remaining faculty participants, two indicated that their only experience teaching has been online. One faculty participant indicated that he has had the same amount of experience teaching online as teaching face to face. The teaching experiences of this group in terms of classroom delivery are quite varied.

\section{FACULTY PERCEPTIONS OF ONLINE AND F2F TEACHING}

\section{A. How Teaching Online and F2F Compare}

Faculty participants felt that there was no significant difference between teaching online and face-to-face. They noted that the major components of the actual classroom were similar, but the amount of time and the interaction with students was very different. They noted repeatedly that the one characteristic that distinguishes online teaching from face to face is students' expectations of faculty availability. The faculty participants feel that online students expect them to be accessible at all times and want immediate feedback from questions, comments and assignments. This expectation along with responding to students' questions individually takes up a lot of time. Faculty participants noted that responding to 
students and preparing the course take considerably more time than teaching a traditional face-to-face course.

Participants in this study appeared to emphasize certain aspects of the process of teaching and learning. When asked what their personal emphases were in their classroom instruction, many noted communication, empathy, personalization, keeping student's interest and attention, class organization, and staying on top of the literature and research in their respective areas. None of the faculty participants made mention of learning outcomes for students.

\section{B. Online Class Management}

The IPI faculty participants were asked also to describe the management of their online classes. All participants concurred that a reasonable range of postings by students was 50-100 for the semester. In terms of a reasonable range of postings by themselves as instructors of these classes, their responses ranged from 50-100 postings to 251-300 postings. The majority of the sample (6 out of 8 ) tended to feel that 50-200 postings were adequate. The remaining two faculty participants felt that 200-300 postings within one semester were a reasonable amount. Accordingly, in classes with 22 students one could anticipate 2.35 to 9 student responses, on average, across all class conferences. Interestingly, the actual amount of postings in a semester described by Kenaszchuk [15] and faculty participants' indications of what was a reasonable range of postings by students during an online class was very similar.

Faculty participants were asked how they would assess the adequacy of student postings. Most faculty participants indicated that the quality of the posting should be evaluated in terms of whether a student was engaging in critical thinking or meeting module goals. The remainder of faculty respondents felt that a content analysis should be conducted or a pre-determined matrix should be set up.

Most respondents indicated that their response to students who enroll and never participate in postings, assignments, and conferences was to contact the student a few times, and if the student was unresponsive, to assign a failing grade in the class.

On average, faculty participants reported spending $18.25(\underline{\mathrm{SD}}=12.70)$ hours a week on activities focused around teaching and managing their online class. Faculty describe a reasonable amount of time students should be focused on course activities as $9.75(\underline{\mathrm{SD}}=8.35)$ hours a week. When asked about average response time for faculty to answer students' questions, the response time was variable (23.38 hours, $\underline{\mathrm{SD}}$ $=11.99$ hours). The range of response times was 7 hours to 48 hours and the modal response was 24 hours. Faculty describe the optimal class size as 20 students $(\underline{\mathrm{SD}}=3.85)$. Most indicated that over 20 students would result in a class that was difficult to manage and to provide prompt communication.

Most faculty participants agreed that the online context was most conducive to a class that was more theoretical and less "hands-on." This optimal class would be based on readings, narratives and discussions and less on demonstrations or technical learning. This group of effective online instructors' response to what the single most important attribute was for an online instructor varied considerably. A prevalent theme that emerged from responses revolved around communicating with students. There were two dimensions to communicating with students, the instructor's and the perceived reception of the communication by students. This cadre of outstanding instructors noted that important attributes for an instructor are such things as ability, accessibility and responsiveness, as well as being organized in terms of communicating with students. With regard to students' perceived reception, faculty participants noted: connecting personally and even deeply, effectively communicating, effectively problem-solving at a 
distance, and even being interesting and engaging.

\section{Profiling the Online Class}

In this section we asked faculty participants to evaluate which components of their classes they relied on for the profile. Most appeared to pay moderate to very little attention to study groups $(\underline{M}=3.13, \underline{\mathrm{SD}}=$ 1.64) and students' use of their web site $(\underline{M}=2.86, \underline{S D}=1.57)$. Generally, their attention was focused more on class-wide conferences $(\underline{\mathrm{M}}=4.75, \underline{\mathrm{SD}}=.71)$, assignments created by instructor and feedback $(\underline{\mathrm{M}}$ $=5.00, \underline{\mathrm{SD}}=.00)$, and completed assignments $(\underline{\mathrm{M}}=5.00, \underline{\mathrm{SD}}=.00)$. Other sections that faculty participants noted they paid attention to were class announcements and chat room and e-mail queries. Overall, when asked to indicate what percentage of their class that was not archived on WebTycho, faculty participants noted on average that it was approximately $25.63 \%(\underline{\mathrm{SD}}=10.84$ : range $=15 \%-$ $50 \%$ ). All indicated that the missing portion of their class did not hinder their ability to evaluate their own classes because they either had hard copies of the missing portions of the archived online classes or they could simply recall what they had done during the tenure of their class.

\section{IPI SELF-ASSESSMENT RESULTS}

\section{A. Faculty Participants}

Across participants, the overall self-assessment rating was $\underline{\mathrm{M}}=4.07(\underline{\mathrm{SD}}=.52$ : see Figure 1 for line graph of individual ratings for each principle). In general, participants expressed an overall agreement with the eight principles of learning both in their ratings and from other sources. But as noted earlier, participants did not always rate specific strategies within these different principles highly. 
Figure 1

Mean Ratings for Teaching Principles Across Faculty Co-Researchers

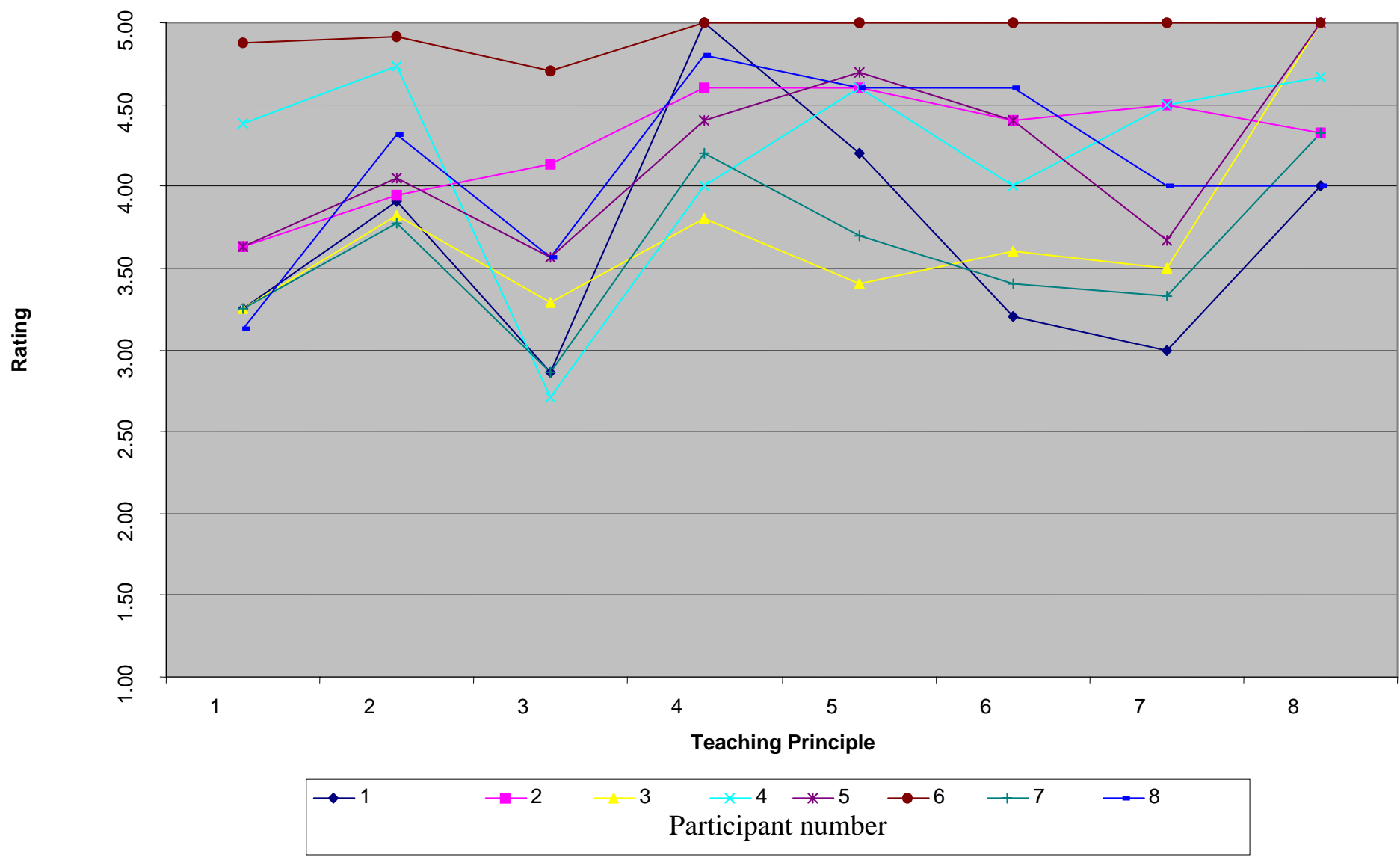

The lowest individual mean rating was $3.58(\underline{\mathrm{SD}}=.86)$. This participant tended not to endorse use of a lot of the IPI strategies because his/her personal teaching style was focused intensely on eliciting active and critical reflection by learners on their growing experience base (principle 5). The highest participant mean rating was 4.92 ( $\underline{\mathrm{SD}}=.26$ : see Figure 2 for individual results). This person is self-described as implementing all of the strategies in the IPI. Interestingly, the participant with the lowest mean rating and the participant with the highest mean rating have taught and currently continue to teach exclusively online for UMUC. Other faculty participants tended to describe themselves as implementing a majority of the strategies, though they were much more varied in their patterns than the participants with the lowest and highest overall ratings. There were three individuals with standard deviations between of 1.00 and above $(1.00,1.03$, and 1.04). The remaining four individuals had standard deviations that ranged from .61 to .86. These standard deviations were significantly higher than those of the participant who was consistently positive in self-assessment ratings $(\mathrm{SD}=.26)$.

The principles eliciting the highest ratings pertained to creating an environment that supports and encourages inquiry (principle $8: \underline{\mathrm{M}}=4.54, \mathrm{SD}=.43$ ); broadening the learners' experience of the subject matter (principle 4: $\mathrm{M}=4.48, \mathrm{SD}=.45$ ); and eliciting active and critical reflection by learners on their growing experience base (principle $5: \mathrm{M}=4.35, \mathrm{SD}=.55$ ). These principles all deal with the learning experience, environment, and community, focusing on the learning process and dynamics of the 
participants in the learning process (i.e., students and instructor).

The principles with the lowest strategy ratings concerned providing an optimal balance of challenge and support tailored to the individual students' readiness and potential (principle 3: $\mathrm{M}=3.46, \mathrm{SD}=.69$ ); clarification of learning goals and the path to them (principle 1: $\mathrm{M}=3.68, \mathrm{SD}=.63$ ); and development of learners' effectiveness as learners early on (principle 7: $\mathrm{M}=4.08, \mathrm{SD}=.63$ ). These principles tend to deal with assessment and tailoring the course for individual students.

Figure 2

Overall Self-Assessment Ratings

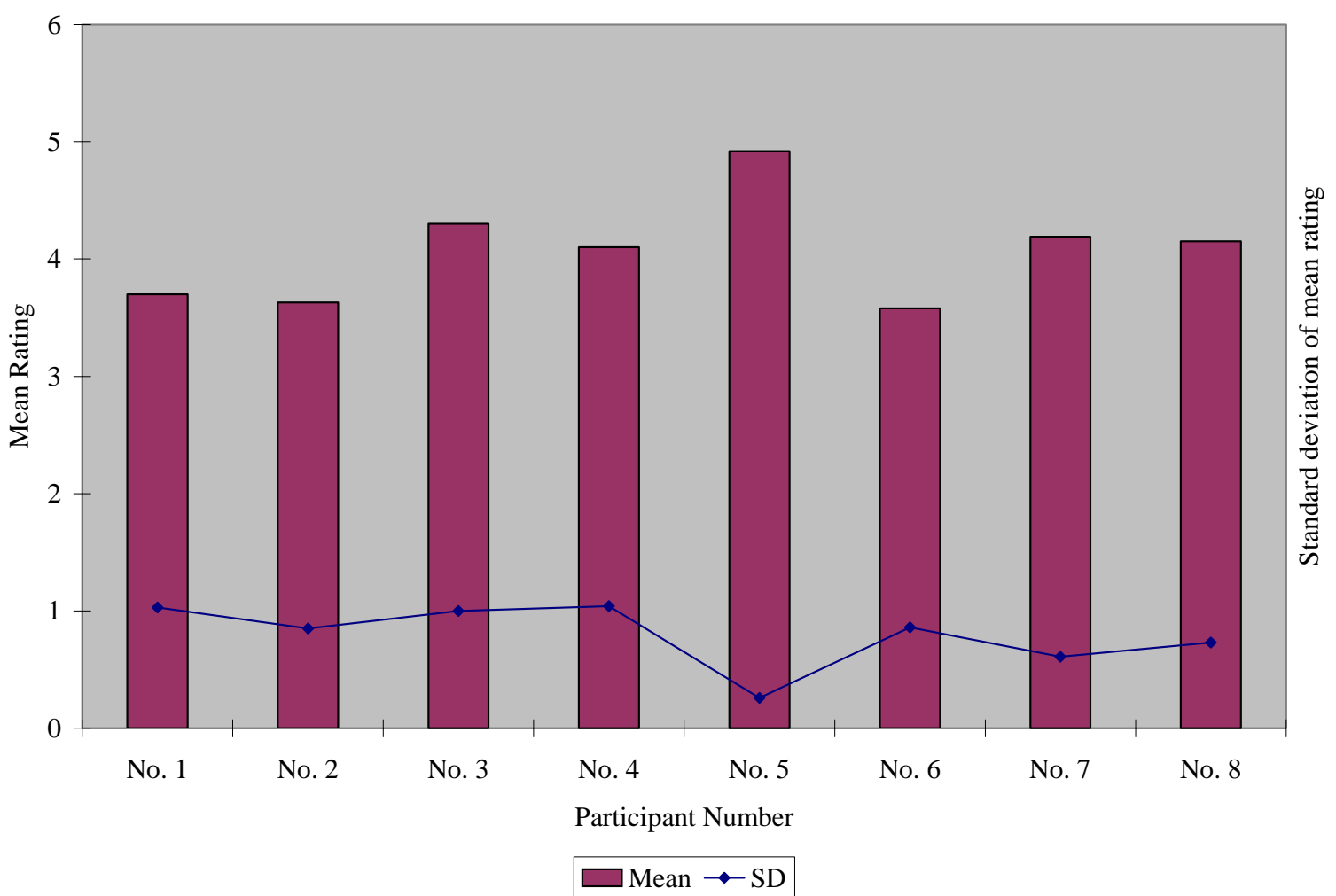

Principles 4, 5, and 8 do not include strategies on student assessment. The strategies involved within each of these principles include creating positive learning environments, promoting interaction between instructor and students and among students, and enabling students to learn from one another. This group of online instructors seemed to emphasize these learning processes most.

The lowest rated principles (1, 3, and 7) are directly related to student assessment, especially assessment of readiness and prior knowledge. In addition to strategies dealing with assessment there were also strategies that centered on clarifying course goals within the principles with low ratings. According to faculty participants, they did not feel they needed to clarify course goals because they had taken the time to carefully prepare and organize the class so that goals were clear to students at the onset of the class; i.e., they excluded time spent before the course from that counted in the profiling. During the second meeting, participants indicated that many of the strategies within the principle that dealt with providing an optimal balance of challenge and support that is tailored to the individual student's readiness and potential (principle 3) were debatable as to whose responsibility it was to assess students' readiness for a course. 
At the crux of their debate was their role in enforcing prerequisites. Many of them stated that they assume a student is ready for their course because there are prerequisites for a course and when courses have been taken and passed in a learning sequence, the student should be adequately prepared for the subsequent class in the sequence. Many of the strategies within principle 3 related to assessing a student's readiness for a course, which the respondents thought was achieved through prerequisites or institutional admission standards for entry-level courses.

Though the instructors profiled clarifying goals low, they seem to have meant, not that they left the goals unclear, but that they needed little or no further effort after the syllabus to do so. Similarly, their low rating of some of the support strategies seems to rest on their view that these support strategies were the responsibility of others. Their limited focus on assessment of learning outcomes appears, not to be unconcern about the outcomes, but a conviction that if the learning processes were sound one could be sure of the outcomes.

The only significant differences that emerged between sub-groups of faculty participants were about strategies within the principle that relates to providing an optimal balance of challenge and support that is tailored to the individual student's readiness and potential (principle 3). The differences that emerged depended upon whether the class was technology-oriented (technology management and computer science management) or non-technology-oriented (psychology, history, administration, and accounting) and a marginally significant difference between genders $(\underline{\mathrm{U}}=.50, \mathrm{P}<.05$ and $\underline{\mathrm{U}}=.05, \mathrm{p}=.06$, respectively: see Figure 3). Generally, technology oriented classes received higher ratings especially on Principle 3. The difference between ratings was significant as noted above (mean rating for technology oriented classes was $4.14, \underline{\mathrm{SD}}=.57$; and non-technological classes was $3.06, \underline{\mathrm{SD}}=.36$ (see Table 3 below). In terms of gender, the only significant difference that emerged was that men rated themselves higher $(\underline{\mathrm{M}}=3.69, \underline{\mathrm{SD}}=.65)$ than did the women $(\underline{\mathrm{M}}=2.79, \underline{\mathrm{SD}}=.10)$ on Principle 3 . This difference emerged because the women in the sample had lower ratings on strategies within principle 3 , which related to providing an optimal balance of challenge and support that is tailored to the individual student's readiness and potential. Both the women in the sample gave low ratings (i.e. "2" or less) to strategies 3.1. 3.2 and 3.7. Strategies 3.1 and 3.2 deal closely with assessing individual students and tailoring course materials based on those individual assessments, and strategy 3.7 deals with requiring students in need of remedial work to seek special services. Strategy 3.7 was not highly rated (i.e., a rating of four or five) by the majority $(2 / 3)$ of the participants. There were no other significant differences between genders on the other principles. 


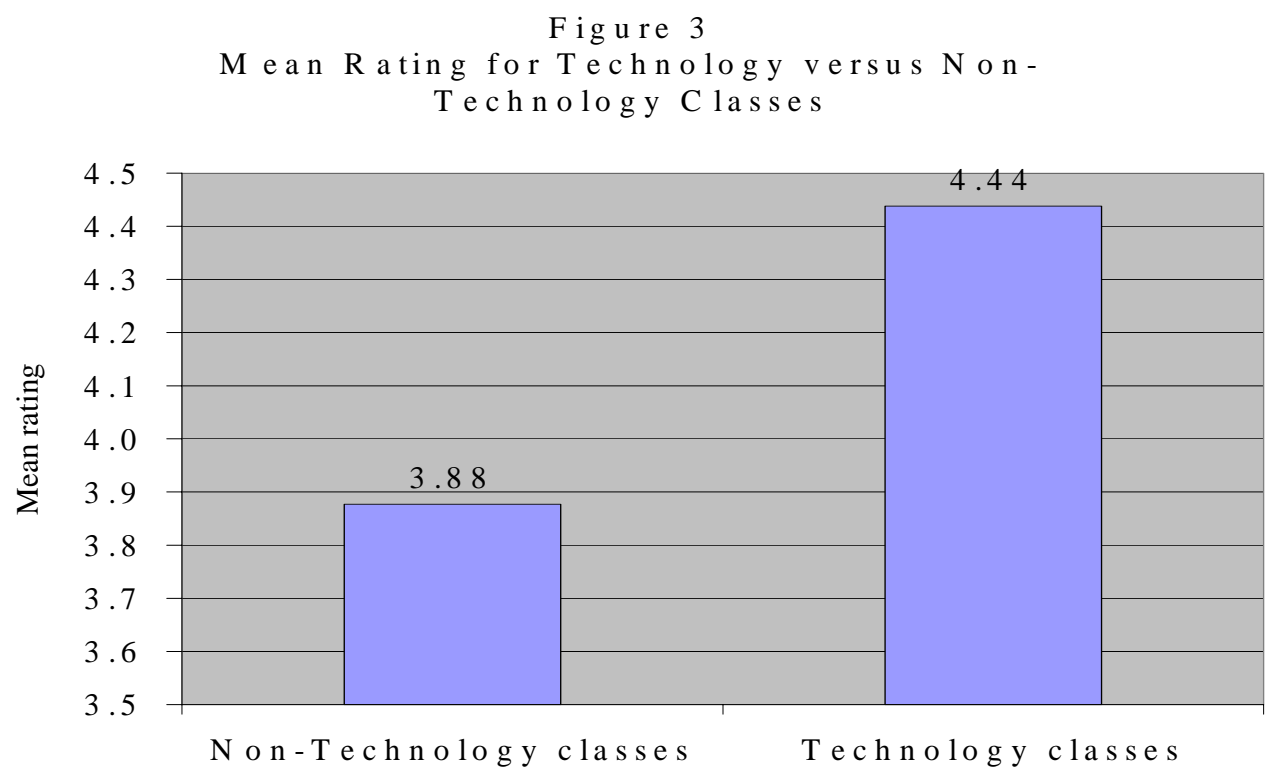

This group of faculty came from a variety of teaching experience levels in both face to face instruction and online instruction and from a wide variety of teaching backgrounds. We know that overall they were quite positive in their ratings of IPI strategies. They expressed a general agreement with the principles, but were not necessarily likely to use specific strategies, especially strategies that dealt with student assessment and clarifying course goals (principles 3 and 1). The emphasis for this group of instructors was on the learning experience for the student. In all their responses they were focused on making the time between the first day of class and last day of class meaningful, interesting and applicable in the student's every day life. They wanted to broaden the student's knowledge base, elicit active and critical reflection and encourage inquiry.

How is one to interpret the participating faculty's strong endorsement of Principle 8's focus on a climate of inquiry with their lesser concern with individualization of instruction and assessment of learning gains and outcomes? Would the large size of UMUC (over 75,000 unduplicated headcount per year) create a climate with this mix of priorities? (With class sizes normally around 23 to 25 students, would that large institutional size affects such priorities?) It seems more likely that the high demand on faculty time for interaction online with students might cause a lessening of attention to individual needs and to the measurement of learning gains and outcomes? Does the fact that UMUC students are overwhelmingly mature adults with five or more years of work experience and with clarity of their purposes in returning to college [16] mean that they will see to getting the help they need? Another factor in this pattern may be that faculty is less expert in assessment than is needed for them to give it a priority in the limited time they have available.

\section{OTHER RESULTS FROM INSTRUCTIONAL PRACTICE INVENTORY}

\section{A. Results Across Faculty Participants}

The learning principle that involves creating an institutional environment that supports and encourages inquiry (Principle 8$)$ was associated with the highest ratings $(\underline{M}=4.54, \underline{S D}=.43$ : see Table 1 below for a 
ranking of principles based on the aggregate of means for strategies within each principle). This group of effective online practitioners indicated that they employed strategies that aimed at making UMUC an institution that supported and encouraged active student inquiry. The principle that entailed broadening the learner's experience of the subject matter (principle 4), had the next to highest aggregate strategy ratings $(\underline{M}=4.47, \underline{S D}=.45)$. In subsequent discussions and meetings with faculty involved in this study, it was evident that this was a very important principle for these instructors. This group of outstanding instructors noted that broadening a student's experience of the subject matter was at the core of the construction and preparation of their courses.

Table 2: Ranking of Principles Based on Aggregate Mean of Strategies

\begin{tabular}{|l|l|l|}
\hline Principle & Mean & SD \\
\hline 8: Create an institutional environment that supports and encourages inquiry. & 4.54 & .43 \\
\hline 4: Broaden learners' experience of the subject matter. & 4.48 & .45 \\
\hline 5: Elicit active and critical reflection by learners on their growing experience base. & 4.35 & .55 \\
\hline 2: Use of deliberate practice and providing prompt constructive feedback. & 4.18 & .43 \\
\hline $\begin{array}{l}\text { 6: Link inquiries to genuine problems or issues of high interest to the learners to enhance } \\
\text { motivation and accelerate their learning. }\end{array}$ & 4.08 & .63 \\
\hline 7: Develop learners' effectiveness early in their education. & 3.94 & .68 \\
\hline 1: Make learning goals and path to them clear. & 3.68 & .63 \\
\hline $\begin{array}{l}\text { 3: Provide an optimal balance of challenge and support that is tailored to individual } \\
\text { students' readiness and potential. }\end{array}$ & 3.46 & .69 \\
\hline
\end{tabular}

In contrast, Principle 3 (provide an optimal balance of challenge and support that is tailored to the individual student's readiness and potential) was associated with the lowest strategy ratings. Nearly all (6 out of 7) of the strategies within this principle received less than an "agree" (4) indication. This principle involved tailoring the class to the individual students' readiness and potential. Faculty members participating in this project felt that they did try to tailor many aspects of their classes to the individual student. They seem to feel, as already stated, that assessing a student's readiness and potential for a class was not part of their job description and also not something they did in their classes. Principle 1, making learning goals and paths to them clear, received the next lowest in terms of the overall ratings obtained, with 5 out of 8 items described as not clearly implemented (i.e., a "3" or less: see Table 1 for an overall ranking of principles based on mean rating). It appears that faculty simply did not use some of the strategies within this principle.

As noted previously, the results of the self-assessment indicate that faculty participants emphasize broadening the learners' experience of the subject matter (principle 4) and eliciting active and critical reflection by learners on their growing experience base (principle 5). They also support and encourage students to question ideas or even to question the instructor's views (principle 8). They appear to emphasize these principles to the exclusion of principles that entail tailoring instruction to the individual student's readiness or potential (principle 3) and any aspect of a principle that involves revisiting and/or revising any portion of their class after having prepared and presented the class to students (portions of principle 2, principle 6 and principle 7).

Across online class profiles, faculty tended to endorse most of the teaching strategies described in the IPI in their classes. Approximately two-thirds of the statements were rated positively by faculty participants. 
For 47 out of 66 statements the strategy ratings ranged between agree and strongly disagree (4 and 5, respectively) on the five-point Likert scale (see Table 2 below for the top five strategies based on mean ratings and Table 3 and the end of this paper for an overall ranking of strategies). This suggests that these 47 different strategies were more than likely used by instructors in their online classes. Neutral (3) ratings tended to indicate that these instructors did not report a clear implementation of a specific strategy within their online course, but to some degree that strategy may have been used in conducting the course. Disagree or strongly disagree ( 2 and 1, respectively) ratings tended to indicate that the instructors did not implement the strategy in their course at all.

Table 3: Top 5 Individual IPI Strategies Rank Ordered from Highest to Lowest Mean

\begin{tabular}{|l|l|l|l|}
\hline Rank & Strategy & Mean & SD \\
\hline 1 & $\begin{array}{l}\text { Students are encouraged to incorporate their individual experiences (e.g., on the job or } \\
\text { personal) in their studies (4.1). }\end{array}$ & 0.71 \\
\hline 2 & $\begin{array}{l}\text { The instructor's expertise is made available to students who need assistance in } \\
\text { distinguishing relevant from irrelevant information (2.5.2). }\end{array}$ & 4.63 & 0.52 \\
\hline 3 & $\begin{array}{l}\text { The instructor's expertise is made available to students who need assistance in } \\
\text { distinguishing poor from high quality resources (2.5.3). }\end{array}$ & 0.63 \\
\hline 4 & $\begin{array}{l}\text { Students' experiential background is used to help master the subject matter (4.5). } \\
\text { The instructor provides opportunities for collaborative learning (e.g., participation in } \\
\text { groups that share experiences, perspectives, questions, alternative explanations of } \\
\text { experience, and different ways of reading situations-discussing with others on issues) } \\
\text { (5.2). }\end{array}$ & 0.52 \\
\hline
\end{tabular}

\section{B. Results across Instructional Practice Principles}

The instructional practice principles are here discussed in terms of constituent strategies in order of their highest to lowest aggregate mean rating.

\section{Principle 8: Create an institutional environment that supports and encourages inquiry.}

Table 4: Mean Ratings for Principle 8 Strategies

\begin{tabular}{|l|l|l|}
\hline Strategy & Mean & SD \\
\hline The instructor actively and enthusiastically encourages students to question ideas (8.1). & 4.63 & 0.52 \\
\hline $\begin{array}{l}\text { The instructor invites and responds amicably to student criticism or questioning of the } \\
\text { instructor's views (8.2). }\end{array}$ & 4.63 & 0.52 \\
\hline $\begin{array}{l}\text { The instructor assists students in their exercise of the discipline-specific methods of inquiry } \\
(8.3) .\end{array}$ & 4.43 & 0.53 \\
\hline
\end{tabular}

As described previously, the principle that garnered the highest aggregate mean rating for strategies related to each principle was the principle for creating an environment that supports and encourages inquiry (principle 8$), \underline{M}=4.57$ ( $\underline{\mathrm{SD}}=.51$ : see Table 4 for mean strategy ratings). This principle had the least amount of strategies (three in total). The range of responses to statements relating to principle 8 was restricted to the ratings of 4 and 5 across faculty participants (see Table 5 in the appendices for the proportion of endorsement by participants across strategy ratings). 
It seems that all faculty agreed that they encouraged inquiry and aided in the creation of an institutional environment that also supported inquiry on the part of the student. The endorsement of these strategies gives support to the idea that faculty participants are focused more on creating a learning environment that promotes learning than on measuring to confirm that the anticipated learning actually occurs. This is not to say the student outcomes are not important to these faculty participants, but rather through the various sources gathered from these participants it seems they feel that the focus on the environment and processes of learning will surely lead to learning on the student's part.

\section{Principle 4: Broaden the learners' experience of the subject matter.}

Table 5: Mean Ratings for Principle 4 Strategies

\begin{tabular}{|l|l|l|}
\hline Strategy & Mean & SD \\
\hline $\begin{array}{l}\text { Students are encouraged to incorporate their individual experiences (e.g., on the job or } \\
\text { personal) in their studies (4.1). }\end{array}$ & 4.75 & 0.71 \\
\hline Students are introduced to cultures or subcultures that may be new to them (4.2). & 4.50 & 0.76 \\
\hline The instructor uses role-playing or simulations to supplement learning (4.3). & 4.00 & 0.93 \\
\hline Students are exposed to different applications of the course subject matter (4.4). & 4.50 & 0.53 \\
\hline Students' experiential background is used to help mater the subject matter (4.5). & 4.63 & 0.52 \\
\hline
\end{tabular}

The principle of broadening the students' experience base (Principle 4) had the second highest mean aggregate rating, $\underline{\mathrm{M}}=4.48(\underline{\mathrm{SD}}=.72)$. The strategy with the lowest mean (see Table 6 above) pertained to role-playing or simulation as ways the instructor supplements learning (\#4.3). This was the only strategy associated with this principle to receive low ratings from a participant. The strategy with the highest ratings pertained to encouraging students to incorporate their individual experiences into their studies (\#4.1).

Again, this principle on broadening the learner's experience with the subject matter is, like the previous principle pertaining to creating an environment that encourages inquiry, focused on the process portion of the classroom rather than on the outcome.

\section{Principle 5: Elicit active and critical reflection by learners on their growing experience base.}

Table 6: Mean Ratings for Principle 5 Strategies

\begin{tabular}{|l|l|l|}
\hline Strategy & Mean & SD \\
\hline Students are encouraged to consider alternative interpretations of their experience (5.1). & 4.38 & 0.74 \\
\hline $\begin{array}{l}\text { The instructor provides opportunities for collaborative learning (e.g., participation in groups } \\
\text { that share experiences, perspectives, questions, alternative explanations of experience, and } \\
\text { different ways of reading situations_-discussing with others on issues) (5.2). }\end{array}$ & 0.52 \\
\hline Students are encouraged to explore alternative problem-solving strategies (5.3). & 4.38 & 0.74 \\
\hline Students check their own inferences for validity (5.4). & 4.13 & 0.83 \\
\hline Students check others' inferences for validity (5.5). & 4.00 & 0.76 \\
\hline
\end{tabular}




\begin{tabular}{|l|l|l|}
\hline $\begin{array}{l}\text { Students are encouraged to question and monitor the credentials of alleged authorities in the } \\
\text { field (5.6). }\end{array}$ & 4.00 & 0.76 \\
\hline Students are encouraged to question assumptions made by others and themselves (5.7). & 4.50 & 0.76 \\
\hline Students conduct research or case analyses that are well-designed (5.8). & 4.50 & 0.76 \\
\hline Students are helped to recognize what they can learn from their own experiences (5.9). & 4.63 & 0.52 \\
\hline Students are encouraged to think about the effectiveness of their own thinking (5.10). & 4.38 & 0.92 \\
\hline
\end{tabular}

Faculty respondents reported the use of nearly all of the strategies pertaining to eliciting active and critical reflection by learners on their growing knowledge base (Principle 5). The majority of ratings obtained $(85 \%)$ were positive in terms of the various strategies. The overall mean rating for statements pertaining to principle 5 was $4.35(\underline{\mathrm{SD}}=.73)$.

Eliciting active and critical reflection of a growing knowledge base is another principle that emphasizes the process of learning rather than the outcome. Given the results of the data it seems to follow logically that the strategies within this principle would receive high ratings overall. But, as with other principles, not all the strategies are used and this may simply mean that these faculty members are successful in their teaching without the use of these strategies.

\section{Principle 2: Use of deliberate practice and providing prompt constructive feedback.}

Table 7: Mean Ratings for Principle 2 Strategies

\begin{tabular}{|l|l|l|}
\hline Strategy & Mean & SD \\
\hline Time on task is always sufficient to the needs of each individual student (2.1.1). & 4.25 & 0.71 \\
\hline Skill building occurs in manageable steps (2.1.2). & 4.50 & 0.53 \\
\hline $\begin{array}{l}\text { Learners are actively engaged in determining their own learning objectives and thus become } \\
\text { co-owners of the learning agenda (2.1.3). }\end{array}$ & 4.00 & 0.53 \\
\hline Deliberate practice is incorporated in learning efforts (2.1). & 4.50 & 0.53 \\
\hline Performance is continually assessed (2.2.1). & 4.50 & 0.53 \\
\hline Learners are encouraged to assess their own progress (2.2.2). & 3.88 & 0.83 \\
\hline Progress on learning goals is continually assessed (2.2) & 4.00 & 1.07 \\
\hline Feedback is continually provided throughout the learning process (2.3.1). & 4.50 & 0.76 \\
\hline Feedback identifies achievements, errors, and causes of errors (2.3.2). & 4.38 & 0.92 \\
\hline Students' own self-assessments of progress and performance are elicited (2.3.3) & 3.63 & 1.06 \\
\hline Feedback about student performance and progress is provided frequently and in detail (2.3). & 4.13 & 0.99 \\
\hline $\begin{array}{l}\text { The instructor consistently notices and remarks on students' effectiveness in their learning } \\
\text { efforts (2.4.1). }\end{array}$ & 4.00 & 1.07 \\
\hline The instructor explains how to correct student errors and shortcomings (2.4.2). & 4.00 & 1.07 \\
\hline A feedback strategy or process is articulated and agreed upon with learners (2.4.3). & 3.63 & 1.30 \\
\hline Feedback provided is consistently constructive (2.4). & 4.50 & 0.53 \\
\hline $\begin{array}{l}\text { Students are made aware of tools and resources that can speed up or enhance their learning } \\
\text { (2.5.1). }\end{array}$ & 4.63 & 0.52 \\
\hline $\begin{array}{l}\text { The instructor's expertise is made available to students who need assistance in distinguishing } \\
\text { relevant from irrelevant information (2.5.2). }\end{array}$ & 4.63 & 0.52 \\
\hline
\end{tabular}


The instructor's expertise is made available to students who need assistance in distinguishing 4.13 poor from high quality resources (2.5.3).

The instructor's expertise is made available to students who need assistance in distinguishing 4.25 soundly developed information from misinformation (2.5.4).

Access to instruction is made convenient and affordable as to times, places, methods, and 4.25 tools of learning (2.5.5).

The instructor recognizes and adapts to individual differences in students (e.g., different 3.75 styles and strengths or weaknesses in learning (2.5.6). Students get resources and tools needed to overcome obstacles to learning goals (2.5). 4.00

Faculty participants' ratings of strategies within Principle 2 were overall positive and less variable $(\underline{M}=$ $4.18(\underline{\mathrm{SD}}=.83)$. The strategy obtained the lowest ratings (only .50 of sample selected the "agree" and "strongly agree" options. The remainder of Principle 2 items rarely elicited negative ratings (7 out of 176 responses in this section were rated as not employed). Also, only $15 \%$ (26 out of 176) of the total ratings for strategies related to Principle 2 were "neutral."

In comparing participants' responses to principle 2 and their accounts of what is a reasonable amount of postings for themselves and students during a semester, no apparent pattern emerged. Participants who perceived that a reasonable amount of postings for themselves during a semester should be at least three times that of students' postings had equal ratings on principle 2 as those who felt that instructor postings did not have to be more than 2 times the amount of students'. In terms of providing prompt feedback, all participants indicated that they did not let more than 24 hours go by before replying to a student's inquiry.

This principle pertaining to the use of deliberate practice and providing prompt constructive feedback is one of the more complicated principles in terms of the strategies needed to achieve the implementation of the principle. There are three overarching strategies and several sub-strategies relating to the overarching strategy (the overarching strategies are in bold and the sub-strategies relating to each of the overarching strategies precede them in the table). There are five strategy groups within principle 2 . The different strategy groups deal with: (1) incorporating deliberate practice $(2.1 .1,2.1 .2,2.1 .3$ and 2.1), (2) assessing progress on learning goals $(2.2 .1,2.2 .2$ and 2.2), (3) providing frequent and detailed feedback about student performance $(2.3 .1,2.3 .2,2.3 .3$, and 2.3$)$, (4) providing consistently constructive feedback (2.4.1, 2.4.2, 2.4.3, and 2.4), and (5) getting students the resources they need to overcome obstacles to learning goals $(2.5 .1,2.5 .2,2.5 .3,2.5 .4,2.5 .5,2.5 .6$, and 2.5$)$. These strategy groups are all somewhat different in terms of their focus on how to incorporate deliberate practice and provide feedback, but one pattern emerges with the lowest rated strategies within each group. These low rated strategies all involve either engaging the individual student in reflecting upon their own progress or goals or tailoring specific portions of their instruction to the individual student. Tailoring and individualizing the class to each student is not perceived as necessarily an important component of online instructional success, given that this group of faculty participants was chosen on the basis of positive recommendations and class evaluations. It is not as if these faculty members don't pay individual attention to their students; rather they will give students individual attention when students ask for it or it is apparent they need it, but they do not appear to make prior instructional plans for each student. 


\section{Principle 6: Link inquiries to genuine problems or issues of high interest to the learners to enhance motivation and accelerate their learning.}

Table 8: Mean Ratings for Principle 6 Strategies

\begin{tabular}{|l|l|l|}
\hline Strategy & Mean & SD \\
\hline $\begin{array}{l}\text { The instructor learns of students' problems relevant to the course and uses this information in } \\
\text { developing instruction (6.1). }\end{array}$ & 4.13 & 1.13 \\
\hline $\begin{array}{l}\text { The instructor poses learning tasks in terms of solving problems or using opportunities rather } \\
\text { than in terms of accumulating knowledge (6.2). }\end{array}$ & 4.50 & 0.53 \\
\hline The instructor draws actively upon the current or earlier work life of the students (6.3). & 4.38 & 1.06 \\
\hline $\begin{array}{l}\text { The instructor elicits student analysis of what worked and did not in their problem-solving } \\
\text { experiences (6.4). }\end{array}$ & 4.38 & 0.74 \\
\hline $\begin{array}{l}\text { The instructor relates the learning objectives of the course to students' need for licensure or } \\
\text { certification (6.5). }\end{array}$ & 3.00 & 1.07 \\
\hline
\end{tabular}

The overall mean rating for statements pertaining to this principle was 4.08 ( $\underline{\mathrm{SD}}=1.05$ : see Table 11 for mean strategy ratings). Strategy 6.5 (not universally applicable and thus perhaps undervalued) drags down the overall ratings of the principle from 4.35 to 4.08 and from third in the ranking to fifth. Three-quarters $(75 \%)$ of the ratings for the strategies relating to Principle 6 were positive. The strategy concerning relating learning objectives of the course to students' need for licensure or certification obtained the lowest mean rating (presumably few of the students lack needed credentials). The highest mean rating was a strategy in which the instructor poses learning tasks in terms of problem solving or opportunities for application (see Table 8 above for mean and standard deviation).

\section{Principle 7: Develop learners' effectiveness as learners early in their education.}

Table 9: Mean Ratings for Principle 7 Strategies

\begin{tabular}{|l|l|l|}
\hline Strategy & Mean & SD \\
\hline $\begin{array}{l}\text { Students are encouraged early in the course to be aware of the importance of being skillful } \\
\text { learners (7.1). }\end{array}$ & 3.63 & 1.06 \\
\hline Students are made aware of the characteristics of highly effective learners (7.2). & 4.00 & 1.07 \\
\hline $\begin{array}{l}\text { Every assignment is designed to enhance students' skills as learners (7.3). } \\
\text { become more proficient learners (7.4). }\end{array}$ & 4.63 & 0.52 \\
\hline $\begin{array}{l}\text { Students' skills as learners are assessed at the beginning of the learning experience (7.5). } \\
\text { Students are encouraged to use tools and skills that enhance their learning while also saving } \\
\text { their time (7.6). }\end{array}$ & 3.25 & 0.71 \\
\hline
\end{tabular}

The overall mean rating for statements pertaining to this principle was $3.94(\underline{\mathrm{SD}}=.93)$. The most highly supported strategy concerned designing every assignment so as to enhance students' skills as learners (\#7.3). The statement associated with the lowest mean rating concerned an initial evaluation of students' skill as learners prior to the onset of the learning experience. Again, this finding seems to underscore the faculty's perception that the department's program administrators or advisors should shoulder the responsibility for skill assessment. 
The strategies within this principle (develop learners' effectiveness as learners early in their education), received variable ratings. The focus of this principle is on making the student an effective learner, which is not always the primary objective of faculty instructors or university departments. The primary objective for many instructors, as well as university departments, is to teach students the material or important aspects of the subject matter. Enhancing students' skills as learners is usually a secondary objective that occurs in pursuit of the primary objective. One reason the ratings for strategies in this section may be less positive is that these faculty members may not have consciously created class activities that are aimed at enhancing skills as learners. Rather these faculty instructors appear to be focused on getting the material out and teaching students the subject matter at hand and a secondary result of meeting this objective would be enhancing their skills as learners.

\section{Principle 1: Make learning goals and the path to them clear.}

Table 10: Mean Ratings for Principle 1 Strategies

\begin{tabular}{|l|l|l|}
\hline Strategy & Mean & SD \\
\hline The instructor makes intended learning outcomes clear (1.1). & 4.50 & 0.53 \\
\hline Goals described in the syllabus are further clarified via discussion (1.2). & 4.13 & 0.99 \\
\hline $\begin{array}{l}\text { Goals are clarified by the use of pre-tests or exercises with assessment tools used to document } \\
\text { learning outcome (1.3). }\end{array}$ & 3.38 & 1.30 \\
\hline Students are encouraged to restate learning goals into their own words (1.4). & 2.63 & 1.06 \\
\hline Instructors encourage students to incorporate their own goals into course work (1.5). & 3.88 & 0.83 \\
\hline Students are provided with concept maps or other graphic representations (1.6). & 2.88 & 1.25 \\
\hline Goals and paths are continually reviewed, revised, or clarified as the course proceeds (1.7). & 3.75 & 1.04 \\
\hline A timeline for learning is clearly spelled out with explicit milestones toward completion (1.8). & 4.25 & 0.46 \\
\hline
\end{tabular}

As previously described, the principle that garnered the next to lowest aggregate rating was principle 1"make learning goals and paths to them clear" (see Table 10 for strategy mean ratings). Overall, faculty co-researchers described themselves as making learning goals and the paths to them clear. The majority of ratings were positive (.66 of all ratings were "agree" to "strongly agree." However, the range of ratings was generally broad with the minimum mean item rating as 2.63 and the maximum mean item rating as 4.50. Faculty participants did not describe themselves as using the strategy that encouraged students to restate learning goals in their own words" (\# 1.4). Nor did they endorse the statement about providing students with concept maps or other graphical representations (\# 1.6). Faculty participants later indicated that the latter question was not clear. Most had no idea of what concept maps were or how they could be used to clarify goals in a course. This question also did not have an explanation as to what other procedures (e.g., course outlining) are regarded as synonymous to concept maps.

Faculty participants reported that they did not continually review, revise, or clarify the course's goals as it proceeded because they perceived that the syllabus stood as a contract between themselves and their students and constantly revising that contract would make the contract null and void (i.e., \#1.7). This is an interesting result of this study that may need further exploration and attention in both IRAHE's and CTL's (Center for Teaching and Learning's) efforts to help faculty improve course instruction.

Making learning goals and their paths clear (Principle 1) and providing an optimal balance of challenge 
and support that is tailored to the individual student's readiness and potential (Principle 3) are both principles that include more outcome-oriented strategies; i.e. strategies are oriented to assessing learning outcomes. This group of faculty participants emphasizes the process of learning rather than the outcome. This is why the strategies relating to these principles are not as likely to be positively endorsed as strategies relating to principles that focus on the process of learning. This is most apparent in the low ratings associated with the strategy pertaining to clarifying the course goals by the use of pre-tests or exercises with assessment tools used to document learning outcome (\#1.3).

\section{Principle 3: Provide an optimal balance of challenge and support that is tailored to the individual students' readiness and potential.}

Table 11: Mean Ratings for Principle 3 Strategies

\begin{tabular}{|l|l|l|}
\hline Strategy & Mean & SD \\
\hline The instructor assesses the students' background and readiness for the course (3.1). & 3.25 & 1.04 \\
\hline $\begin{array}{l}\text { The instructor challenges individual students based on differences in their prior knowledge and } \\
\text { skill levels at the outset of the course (3.2). }\end{array}$ & 1.19 \\
\hline $\begin{array}{l}\text { The instructor provides specific supports related to the risks identified for each student in the } \\
\text { course (3.3). }\end{array}$ & 1.75 \\
\hline The instructor assists students when they most need help with the course work (3.4). & 4.38 & 0.52 \\
\hline $\begin{array}{l}\text { The instructor's expectations of students match student's (self-perceived) levels of promise } \\
\text { (3.5). }\end{array}$ & 0.7 .75 \\
\hline Students in need of remedial work are required to do the extra work on their own (3.6). & 3.13 & 1.36 \\
\hline $\begin{array}{l}\text { Students in need of remedial work are required to seek special services recommended by the } \\
\text { instructor (3.7). }\end{array}$ & 1.38 \\
\hline
\end{tabular}

As previously described, this principle pertaining to tailoring the class to the individual student (Principle 3 ) elicited the lowest mean aggregate rating, $\underline{\mathrm{M}}=3.46(\underline{\mathrm{SD}}=1.16)$. The lowest mean item rating was "encouraging students in need of remedial work to seek special services" (\#3.7). The item with the highest mean rating concerned instructors' assisting students when they most need help with course work (\#3.4) (self-reporting seems to be relatively high on this item). Over half the responses (61\%) appeared to have been used; i.e. the ratings were either "agree" or "strongly agree."

In further discussions with faculty participants concerning this principle, faculty maintained that responsibilities for assessing students' potential and capabilities fall to other University administrators. All faculty participants stated that they simply assumed that a student is ready and capable of taking a class because students are advised to take classes in a sequence and that completion of a class prior in the sequence should adequately prepare a student for the class that follows. The lower ratings for this principle appear to be a reflection of what this group of faculty members felt were, or were not, parts of their job responsibility.

Providing an optimal balance of challenge and support that is tailored to the individual student's readiness and potential is a principle that seems to combine two aspects of instruction within the IPI that are not highly endorsed by faculty participants: these aspects are outcomes assessment and creating individual instructional plans for each student. The focus of faculty participants is most evident in this strategy in that the only strategy to receive a mean rating above a 4.0 is the strategy relating to assisting students when they most need help with the course work (\#3.4). Again, we see that these participants are not 
averse to paying attention or focusing on individual students, but they do so when they see fit or when a student asks.

\section{DISCUSSION}

In summary, the most highly endorsed principles are ones that focused on the processes of learning rather than on the assessment of their outcomes. Faculty participants tended to endorse strategies that related to either assessing students or individualizing the course for each student. These faculty participants were focused on creating an environment that was conducive to interaction and exchange. They found encouraging inquiry and checking the validity of inferences to be important and present in their own classes. This group wanted to make sure they kept students' attention, were responsive to their needs without individualizing the class for each student, and presented material to students that was both interesting and current. These participants also felt (perhaps mistakenly) that enough planning went into creating their online courses so that goals and objectives did not need to be further clarified or revised or reviewed throughout the class.

These faculty participants appear to be following a dynamic learning community model over the alternative teacher-controlled or pre-designed instructional systems [17]. All faculty participants highly endorsed creating an environment that promotes inquiry and supports learning. Many faculty pointed out that they take every opportunity to interact with students, either through threaded discussions within conference models, chat rooms, or even face to face meetings, if possible. Faculty participants noted that UMUC's student population of adult learners provides another avenue to learning within each classroom. Most students have prior experience and learning that they bring with them to the classroom, and it is this prior experience and learning that provides the additional wealth of information to the classroom learning process. Yet, the wealth of information can only be tapped by providing an environment where students feel comfortable and willing to share these experiences, which can explain the emphasis on the learning community and fostering classroom interaction. When students are able to voice opinions, share experiences, and question ideas and instructors are able to interact with students on a mentoring level, then the classroom is a dynamic learning community rather than a pre-designed or teacher controlled course. All of our faculty participants appear to be promoting and conducting classrooms that follow the concept of a dynamic learning community.

Twigg [18] provides an excellent overview of innovations in the field of online learning. She highlights various educational programs that have moved away from the traditional academic practices in higher education (e.g., lecturing, providing readings, and giving a few tests per semester). These programs have moved to practices that make the student a more active learner by: tailoring course activities through an initial assessment of each student's knowledge/skill level and preferred learning style, interactive learning materials and activities, built-in continuous assessment to provide instantaneous feedback, and appropriate and varied types of interaction among students and with the instructor. What is most apparent across these innovations is that different educational programs are focusing on tailoring the online learning experience to the individual student. Tailoring the class to each student appears to be achieved through continual assessment of the student either through intelligence agents or tests. Given the results of our study, this is not something that is overly emphasized at the University of Maryland University College, but this type of tailoring is technologically bound. The programs that Twigg describes appear to be implementing higher levels of technology in their online classes to make these assessments which in turn tailor the online class to the individual student's experience and ability level. Currently at UMUC, we will be implementing a new tool in our WebTycho online classroom that will allow faculty to easily create quizzes and tests that provide instant feedback for the student and allow the instructor to assess learning throughout the course. This tool may aid instructors in implementing more assessment in their online courses than is currently being conducted. 
On separate occasions, faculty participants mentioned that they learned a lot from doing the profiles of their own classes. Many of them noted that they had not thought about teaching and learning the way they are presented in the instructional principles and strategies. Even though many of these ideas may have seemed novel, this group of well regarded faculty still employed many of the strategies within the instructional practices inventory in their online classes. One explanation of why faculty participants may have used these strategies and principles but did not explicitly realize they were using them is that through their teaching experiences they have built a large knowledge base of instructional practices that appear to enhance student learning. That knowledge base was heavily "cross-referenced" across many different teaching and learning experiences. Thus, faculty do not immediately recognize one of their practices when it is written more broadly as, say, a learning principle or more specifically as a teaching strategy (for further discussion on expertise see [19]).

One of the limitations of this study is that it is based on self-reports. In addition, faculty participants indicated that at least one quarter of their class was not archived, so some of the reports may be based on recollection, or the faculty may feel that they implemented a principle, but that implementation might not be obvious to an outside party. This is why we are conducting the second phase of this study, which is a peer review of the online courses included in this study.

\section{ACKNOWLEDGEMENTS}

This paper is abbreviated from a February 14, 2002 report by Marisa Collett, Morris Keeton and Vivian Shayne of the Institute for Research and Assessment in Higher Education, Office of Distance Education and Lifelong Learning, University of Maryland University College.

\section{REFERENCES}

1. Keeton, M. Sheckley, B. \& Krejci-Griggs, J. Effectiveness and Efficiency in Higher Education for Adults. Council on Adult and Experiential Learning. Chicago: Kendall-Hunt, 2002.

2. Chickering, A. W. \& Gamson, Z. Seven Principles for Good Practice in Undergraduate Education. Racine, WI: The Johnson Foundation, 1987.

3. Bonk, C. J. Online Teaching in an Online World. 2001.

Available: http://www.publicationshare.com/docs/faculty_survey_report.pdf.

4. Bonk, C. J. \& Wisher, R. A. Applying Collaborative and E-learning Tools to Military Distance Learning: A Research Framework. (Technical Report \#1107). Alexandria, VA: U.S. Army Research Institute for the Behavioral and Social Sciences, 2000. http://www.publicationshare.com/docs/Dist.Learn(Wisher).pdf.

5. Phipps, R. \& Merisotis, J. What's the Difference? A Review of Contemporary Research on the Effectiveness of Distance Learning in Higher Education. Washington, D.C.: The Institute for Higher Education Policy, 1999.

6. Russell, T. L. The "No Significant Difference Phenomenon." Chapel Hill, NC: Office of Instructional Telecommunications, North Carolina University, 1999.

Available: http://cudateleeducation.nb.ca/nosignificantdifference/.

7. Shea, C. Taking Classes to the Masses. The Washington Post Magazine, 24-25, 28-33. September 16, 2001.

8. Bonk, C. J., Kirkley, J. R., Hara, N. \& Dennen, V. Finding the Instructor in Post-Secondary Online Learning: Pedagogical, Social, Managerial, and Technological Locations. In J. Stepehenson (ed.), Teaching and Learning Online: Pedagogies for New Technologies, 76-97. London: Kogan Page, 2001. 
9. Cho, H. \& LaRose, R. Privacy Issues and Internet Surveys. Social Science Computer Review 17(4): 421-434, 1999.

10. Van Eyde, D. F., \& Spencer, R. W. Lecture Versus Experiential Learning: Their Differential Effects on Long-Term Memory. Journal of the Organizational Behavior Teaching Society 12(4): 52-58, 1998.

11. Lysakowski, R. S., \& Walberg, H. J. Instructional Effects, Cues, Participation, and Corrective Feedback: A Quantitative Synthesis. American Educational Research Journal 19(4): 559-578, 1982.

12. McKeachie, W. J., Chism, N., Menges, R., Svinicki, M. \& Weinstein, C. E. Teaching Tips: Strategies, Research, and Theory for College and University Teachers. Ninth Edition. Lexington, MA: D.C. Health \& Company, 1994.

13. Kehrhann, M., Sheckley, B. G. \& Travers, N. L. "Efficiency and Effectiveness in Graduate Education." Association for Institutional Research File 76: 14. 2000.

14. Sheckley, B. G., \& Keeton, M. T. Improving Employee Development: Perspectives from Research and Practice. Chicago: Council for Adult and Experiential Learning, 1997.

15. Kenaszchuk, C. Online Interaction at UMUC: Message-Posting Statistics from a Sample of Archived, Summer Semester 2000 WebTycho Online Courses. Unpublished manuscript, University of Maryland University College, 2001.

16. King, P. M. \& Kitchener, K. S. Developing Reflective Judgment. San Francisco: Josses-Bass Publishers, 1994.

17. Wilson, B. \& Ryder, M. Dynamic Learning Communities: An Alternative to Designed Instructional Systems. 1994. Available: http://carbon.cudenver.edu/ mryder/dlc.html.

18. Twigg, C. A. Innovations in Online Learning: Moving Beyond No Significant Difference. In The Pew Learning Program, 2001. Available: http://www.center.rpi.edu/PewSym/mono4.html/.

19. Bedard, J. \& Chi, M. Expertise. Current Directions in Psychological Science 1: 135-139, 1992.

\section{APPENDIX A: INSTRUCTIONAL PRACTICES INVENTORY PRINCIPLES \& STRATEGIES}

Principle 1. Make learning goals and paths to them clear.

Strategies:

1.1 State goals and objectives in syllabus and clarify by classroom or online discussion.

1.2 Give pretest or exercises to clarify expected learning outcomes.

1.3 Have students re-state goals in their own words.

1.4 Engage learners in determining learning objectives, including incorporating some of their own related goals into course work.

1.5 Provide or have students develop concept maps/graphic representations of ways to reach goals.

1.6 Review and revise goals and paths to them as course proceeds.

1.7 Spell out timetable/milestones toward course completion.

Principle 2. Use deliberate practice and provide prompt constructive feedback.

Strategies:

2.1 Build skills in manageable steps.

2.2 Provide sufficient time-on-task for each step for each student. 
2.3 Practice each skill until mastery is achieved.

2.4 Learner and teacher/coach assess progress continually/frequently.

2.5 Provide prompt feedback after each assessment.

2.6 Feedback identifies achievements, errors, and causes of errors in detail.

2.7 Feedback includes suggestions on how to correct errors and shortcomings.

2.8 Feedback is consistently constructive.

2.9 Feedback includes information on tools, books, resources, including experts and Web resources.

2.10 Instructor helps distinguish relevant from irrelevant information.

2.11 Instructor helps distinguish poor from high-quality resources, misinformation from soundlydeveloped information.

2.12 Access to instruction is convenient and affordable as to times, places, methods and levels of learning.

2.13 Instructor adapts to individual differences among students; e.g., as to styles, strengths, and weaknesses.

Principle 3. Balance challenge and support to individual's readiness.

Strategies:

3.1 Early on, instructor assesses students' background and readiness for the course.

3.2 Instructor challenges students to go beyond previous levels of knowledge and skill.

3.3 Instructor provides timely support for each student as needed.

3.4 Students needing remedial services are provided appropriate help and required to use it.

Principle 4. Broaden the learners' experience base.

Strategies:

4.1 Students are introduced to phenomena new to them.

4.2 Students are encouraged to relate their individual experiences on the job and in other relations to their studies.

4.3 Students are introduced to subcultural or cultural perspectives new to them.

4.4 Instructor uses role-playing or simulation to supplement direct experience of subject-matter.

4.5 Students are exposed to applications of the subject-matter and skills to diverse types of situation.

Principle 5. Elicit active and critical reflection by learners on their growing experience base.

\section{Strategies:}

5.1 Students are encouraged to consider alternative interpretations of their experience.

5.2 Instructor provides opportunities for collaborative learning (sharing experiences, perspectives, questions, alternative explanations).

5.3 Students are encouraged to explore alternative problem-solving strategies.

5.4 Students check their own and others' inferences for validity.

5.5 Students are encouraged to question and monitor the credentials of alleged authorities in the field. 
5.6 Students are encouraged to question assumptions made by themselves and others.

5.7 Students conduct research or case analyses that are well designed.

5.8 Students are helped to recognize what they can learn from their own experiences.

5.9 Students are encouraged to think about the effectiveness of their own thinking.

Principle 6. Link inquiries to genuine problems of high interest to the learners.

Strategies:

6.1 Instructor learns of students' problems relevant to the course and uses the information to develop instruction.

6.2 Instructor poses learning tasks in terms of solving problems or using opportunities rather than accumulating knowledge.

6.3 Instructor draws actively on current or earlier work life of the students.

6.4 Instructor elicits student analysis of what worked and did not work in their problem-solving experiences.

6.5 If relevant, instructor relates learning objectives of the course to licensing or certification requirements.

Principle 7. Develop students' effectiveness as learners.

Strategies:

7.1 Students are encouraged early in course to be aware of the importance of being a skillful learner.

7.2 Students are made aware of the characteristics of highly effective learners.

7.3 Every assignment is designed to enhance students' skills as learners.

7.4 Students are encouraged to monitor their own learning habits and to evaluate their efforts to become more proficient learners.

7.5 Students' skills as learners are assessed at the beginning of the course.

7.6 Students are encouraged to use tools and skills that enhance their learning while also saving their time.

Principle 8. Contribute to an institutional environment encouraging inquiry.

Strategies:

8.1 Instructor actively and enthusiastically encourages students to question ideas.

8.2 Instructor invites and responds amicably to student questioning or criticism of the instructor's views.

8.3 Instructor assists students in their exercise of discipline-specific methods of inquiry. 


\section{APPENDIX B: COURSES INCLUDED IN STUDY}

\section{A. UNDERGRADUATE COURSES}

\section{PSYC 221}

Social Psychology (3 credits)

Prerequisite: PSYC 100. An examination of the influence of social factors on individual and interpersonal behavior. Topics such as conformity, attitudinal change, personal perception, interpersonal attraction, and group behavior are covered. Students may receive credit for only one of the following courses: BEHS 221, PSYC 221, or (former courses) BEHS 421 or BEHS 450.

\section{TMGT 310}

\section{Problem Solving ( 6 credits)}

Presentation of the theoretical and practical aspects of strategies used in solving problems, an activity that takes up much of the manager's day. Approaches evaluated include holistic thinking, the use of analogy, internal brainstorming and other methods of creative thinking, the development of an ability to shift perspectives, the scientific method, the analysis of language, systems analysis, and graphic representations. Case studies are used to illustrate the definition of the problem, the formulation of hypotheses, and the collection and analysis of data.

\section{ACCT 326}

Accounting Information Systems (3 credits)

Prerequisites: ACCT 321 and a course in information systems management, or equivalent. A study of the control aspects of accounting systems. Topics include setting standards; defining and imposing administrative, operational, and security controls; judging cost-effectiveness of systems; and understanding the effects of a computer-based information environment on the possibilities of being audited. Various techniques are used to study accounting information-systems concepts; these may include the use of problem sets, case studies, computer applications, and other materials. Students may receive credit only once under this course number and for only one of the following courses: ACCT 326 or (former courses) BMGT 320 or BMGT 326.

\section{HUMN 119}

American Adventure (3 credits)

(Fulfills the historical perspective requirement.) A survey of the early history of the United States, covering the discovery of the New World through the Civil War and Reconstruction. Emphasis is on social history, including the effects of political and social events on women, children, the family unit, African Americans, and Native Americans. The clash between European and Native American cultures, the violence of the revolution, and trials and tribulations of the early pioneers are explored. Materials from the telecourse "The American Adventure" are integrated with the course. Students may receive credit for only one of the following courses: HIST 156 or HUMN 119. 


\section{B. GRADUATE COURSES}

\section{TMAN 614}

Strategic Management of Technology \& Innovation (3 credits)

Students apply strategic analysis techniques to business policy and organizational development. Emphasis is placed on linking technology policy with corporate strategy and on identifying technology options appropriate for the business or organizational strategy being executed. Topical coverage includes historical perspectives on strategic technology planning, external and internal strategic analysis, technology forecasting, benchmarking, corporate intelligence, and implementation and control strategies. Note: This course replaces TMAN 605.

\section{CSMN 636}

Telecommunications and Connectivity ( 3 credits)

The fundamentals of data communication systems and technologies are examined. Students explore these technologies from the perspective of the current and future public-switched network, wide area networks, and local area networks. Also addressed are network architectures, networking standards, digital and analog signals, and the various transmission media. Future trends in data communication concepts, equipment, applications, and services, including the open systems interconnection (OSI) model, T-1/T-3 multiplexers, fiber optics, integrated voice/data equipment, "intelligent networks," and the Integrated Services Digital Network (ISDN) are also discussed.

\section{ADMN 625}

Organizational Communication \& Group Development (3 credits)

This course investigates the theories and research related to communication and group development within modern organizations. It examines definitions, models, and barriers, including structural, psychological, and technological factors. It investigates current issues, such as the impact of the global environment, cultural diversity, and virtual environments. It includes strategies and methods for managing conflict and managing change. Interpersonal, small group and large group settings are addressed. Managerial application of the concepts is stressed.

\section{4. $A D M N 666$}

Recruitment and Selection ( 3 credits)

This course examines the initial phases of staffing, focusing on the hiring process. It investigates the contemporary roles, relationships, and processes of recruitment and selection in the human resource management system. It highlights productivity factors (such as the use of technology) and quality factors (such as legal, ethical, and validity issues). It includes international as well as domestic concerns and consideration of multiple staffing levels (such as executive managers and temporary employees). Current issues in private, not-for-profit, and/or public sectors are discussed. 